\title{
Specification a Model for Study of Local Development
}

\author{
Cruz García Lirios* \\ Academic Trans disciplinary Network, México \\ *Corresponding author: Academic Trans disciplinary Network, México
}

Received: 笽 December 10, 2019

Published: 眥January 23, 2020

\begin{abstract}
The relationships between personal and group variables are specified with respect to water availability and supply management. The work contributes to the discussion around the administration of water resources and services based on social variables such as resilience, solidarity and cooperation. In this sense, the parameters that allow management based on local consumption needs are exposed. Within the framework of Human Development, the weighting of needs and water availability is fundamental for the establishment of an agenda in the area of water supply management.
\end{abstract}

Keywords: Water Availability; resource Management; environmental participation; water supply; local development

\section{Introduction}

The formalization of the relationships between risk events and management instruments related to local development was the objective of this work, considering a documentary study with an intentional selection of sources indexed to Dialnet, Latindex, Publindex, Redalyc and Scielo, as well as the keywords. For the purposes of this work, local development is understood as a scenario of optimization, entrepreneurship and innovation in the use of public resources with respect to risk events that threaten local development. In this sense, formalization will be understood as the establishment of the axes and discussion topics, as well as the specification of the relationships between these elements. In the framework of the call for research projects for full professors of the National School of Social Work, a research project was developed that began with an exploration of migration in Xilitla, a town located in San Luis Potosí. The indicators of Human Development such as health, housing, education and employment were significantly related to the migration of family members.

However, the permanence in the locality was positively related to the care of the environment, indicated by water saving and reuse. Based on this finding, it was considered that Human Development would be oriented by coffee growing, the main employment activity in the locality Sandoval FR et al. [1]. However, droughts and floods encouraged the production of coffee and its commercialization, since the water culture of Xilitla depended on the rainy season and the regular supply of the public drinking water service. Therefore, by modifying the natural water cycle and exacerbated the water shortage, farmers were affected in their use s and customs, entrepreneurship and marketing Garcia C et al. [2]. The alternative of collecting rainwater, filtering process, reuse and recycling has been considered viable in relation to local entrepreneurship. In this sense, there are significant differences in the acceptance of technology among young people with respect to older adults, but the minimum investment that is required discourages implementation Amemiya $\mathrm{M}$ et al. [3].

In this way, the management that from Social Work can be generated from the ethnography of local needs, the motivation to participate in the care of the environment and the implementation could show the barriers for the acceptance of technology García C [4]. Therefore, a study of the effects of the promotion of the capture, dosage, reuse and recycling technology on local water uses and customs could stimulate coffee production and thereby reactivate Local Development. Will establish a diagnosis of the acceptance or rejection of capture technology, metering, reuse and recycling of water around coffee production of small and medium enterprises to manage subsidies to the authorities and enhance marketing of the product in three locations with high water availability, but low level of social entrepreneurship. If the promotion of the acceptance of technology is aimed at young coffee farmers, then the social entrepreneurship indicated by the demand for subsidies, credits, resources and 
implementation to micro, small and medium enterprises will be activated.

Coffee production will increase by encouraging the training of coffee farmers and expanding the local market to other neighboring communities, but there will be a difference between Xilitla, Valles and Real de Catorce, since their levels of availability and entrepreneurship are different. As availability decreases, social entrepreneurship increases because locals seek to diversify their paid activities. In this sense, coffee growing goes beyond the reactivation of Local Development, its effects on social entrepreneurship will generate a local metabolism.

\section{Formalization}

Accordingly, stage $w$ is extended by the addition of an equation that defines the availability of wastewater $\left(\mathrm{FS}_{\text {sew }}\right.$ ) as it depends on the amount of water consumed by households $\left(\mathrm{QCD}_{\mathrm{cwath}}\right)$ and activities related to a ${ }_{\text {wastewater }}$ system. sewage system ( $\left(\mathrm{WAT}_{\text {cwat,asew }}\right.$ ).

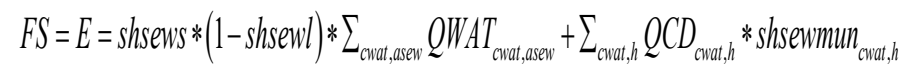

Where the shsewmun coefficients define the shares of water consumed that is taken into account as wastewater, shsews defines the percentage of wastewater collected and shsewl defines the proportion of wastewater collected. The wastewater supply defines the maximum amount available for recycling, but the actual amount used depends on the demand for reclaimed wastewater conditioned on the supply and demand of all types of water in the system. Wastewater that is not recycled leaves the system. There may be environmental reasons to ensure a minimum level of discharge, for example, for natural conservation and improvement of river quality: for convenience, in the model, these discharges are part of government consumption (QGD). Public consumption of wastewater has a lower limit (comgovconst), the amount consumed in the base period, and there is no upper limit. Formally, it is a mixed complementary problem (2), with a lower level than the base quantity (3). The government can adjust the lower limits for different types of water individually or multiplicatively (QGD $\mathrm{ADJ}$ ), for example, in response to environmental concerns about inadequate river flows, etc.,

$$
\begin{aligned}
& \mathrm{QGD}_{\text {cwatrec }}=\mathrm{G}=\mathrm{QGDWADJ}^{*} \text { comgovconst }_{\text {cwatrec. }} \\
& {\mathrm{QGD} . \mathrm{LO}_{\text {cwatrec }}}=\text { comgovconst }_{\text {cwatrec }}
\end{aligned}
$$

Social work for human, local and sustainable development implies the formalization of variables that, due to their relationship of dependence, establish the scenarios for the management and administration of water resources and metropolitan services. In this sense, the contribution of the present work to Social Work for Sustainability lies in the formalization of the relationships between the variables. However, the work of Yuangion Y et al. [5] warn that formalization is only one phase of public policy. The management of water resources and services is not only focused on the supply, but on education and promotion of public health. In this way, the effects of climate change on local health suppose formalization competencies for social work that would be complemented with the management of local needs. This is how, according to Long $\mathrm{H}$ [6] learning about the care and conservation of the environment requires management focused on social entrepreneurship. In this phase of the local development process, the motivation of water saving, and reuse competencies is essential to guarantee the sustainability of the region.

Summer L [7] warns that social work competencies are determined by public management models rather than by community needs. The asymmetries between territorial planning and civil demands would be an object of study from which the social worker would delimit a research approach. Tekeher S [8] argues that the formalization of the asymmetries between the availability of resources and actions in favor of water care guide local decisionmaking. However, the management of social work can start from formalization, but necessarily culminate in the promotion of rights to public health, water supply and the prevention of water crises or conflicts over supply. Long [6] points out that the promotion of rights involves the administration of resources and needs. In this sense, the differences between territorial planning and the management of needs are resolved in interdisciplinary models in which an agenda is established. The water agenda for local development, in the conception of Simsek A [9], goes beyond the asymmetries between government administration and civil self-management. Such differences are resolved, in the first instance, in Information and Communication Technologies (ICTs) and eventually in traditional media.

Finally, the formalization of water supply management is also determined by the perceived risks. In the Bakabulindi $F$ [10] the uncertainty affects the decision-making both governmental and citizen. In this sense, it is necessary to deepen in those scenarios of shortages and shortages that are forecast after climate change intensified droughts. Kotaman $\mathrm{H}$ [11] proposes that the management of sustainability starts from the initial education. From the volitional development, sustainability would be introjected into the habitus of consumption, but it would be consolidated in the stages of cognitive formation. Shaheen Y [12] argues that such a process would be insufficient because environmental contingencies involve decisions of utility and risk. Both factors, the cognitive volitional formation and the risk and utility decisions would be incorporated in the mathematical formalization with the purpose of predicting scenarios of ecological crisis and conflicts for the water supply.

\section{Final considerations}

The present work sustains that the formalization of the variables involved in the water management and consumption process is essential for the promotion of health and the right to 
water. However, some findings and proposals from other disciplines require a comprehensive review of resources and needs, demands and water consumption at the local level.

The Porte the present study the state of the matter lies in formalizing a model for the study of development management, although the intentional selection of data repositories limits the discussion of thematic, suggesting the revision in Copernicus, Ebsco, Scopus and WoS. Sanchez A et al. [13] associated organizational culture local sustainable development to observe the competitive advantages of creative business knowledge to events and risks such as earthquakes, fires, frosts, were following, landslides or snow in relation with cultures of innovative management or resource optimization.

In the present work it has been highlighted that the management of local development depends on the integral management of natural resources, mainly public services of water supply and treatment, although these are implemented in function of risk and corruption events; Negligence, opacity, impunity, nepotism, cooptation or extortion. Limón GA et al. [14] propose that local sustainable development be the product of agreements and responsibilities between governors and the governed with respect to risk events, programs and strategies. In the present study, a model has been specified to address the situation in which political and social actors, as well as the public and private sectors are limited to science and technology in the face of risk events, but the discussion towards of technology and its impact of the relationship between governors and the governed is a line of research to follow.

\section{References}

1. Sandoval FR, Bustos JM, García C (2018) Exploratory contrast of a governance model of local water sustainability. Management of People and Technology 31: 72-87.
2. García C, Juárez M, Bustos JM (2018) Specification of a model for the study of local governance. Synchrony 22(73): 459-472.

3. Amemiya M, Valdés O, Espinoza F, García C (2018) Specification of a model for the study of sustainable local development. Eureka 15 (1): 136-157.

4. García C (2018) Theory of sustainable behavior for local development. Clivajes 5(9): 71-94.

5. Yuangion Y, Yun Chen (2011) The impact of strong ties on entrepreneurial intention. An empirical study based on the mediating role of selfefficacy. Journal of Chinese Entrepreneurship 3(2): 147-158.

6. Long $H$ (2013) The relationships between learning orientation, market orientation, entrepreneurial orientation, and firm performance. Management Review 20: 37-46.

7. Summer L (2011) The Theory of Planned Behavior and the impact of past behavior. International Journal of Economics and Business Research 10(1): 91-110.

8. Tekeher S (2013) Mathematics teacher educator and pre-service teacher's beliefs about the use of technology in teaching in African university. International Journal of Innovative Interdisciplinary Research 12: 9-20.

9. Simsek A (2011) The relationships between computer anxiety and computer self-efficacy. Contemporary Educational Technology 2(3): 177-187.

10. Bakabulindi F (2012) Does use of ICT relate with the way it is perceived? Evidence from Makerere university. International Journal of Computing and ICT Research 6(2): 75-94.

11. Kitman H (2010) Turkish early childhood educators' sense of teacher efficacy. Education and Psychology 8: 603-516.

12. Shaheen Y (2010) The perceived usefulness of information for investment decisions: Evidence from Palestine securities exchange. Hebron University Research Journal 5: 283-307.

13. Sánchez A, Hernández TJ, Martínez E, Villegas E, García C (2018) Organizational culture in micro-enterprises of local development. Margin 89: 1-10.

14. Limón GA, Bustos JM, Juárez M, Rivera BL, García C (2018) Discussion of the endogenous factors of sustainable local development in the governance of water resources. Epsys 14: 1-13.

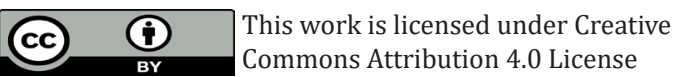

To Submit Your Article Click Here:

Submit Article
DOI: 10.32474/OAJCAM.2020.02.000134

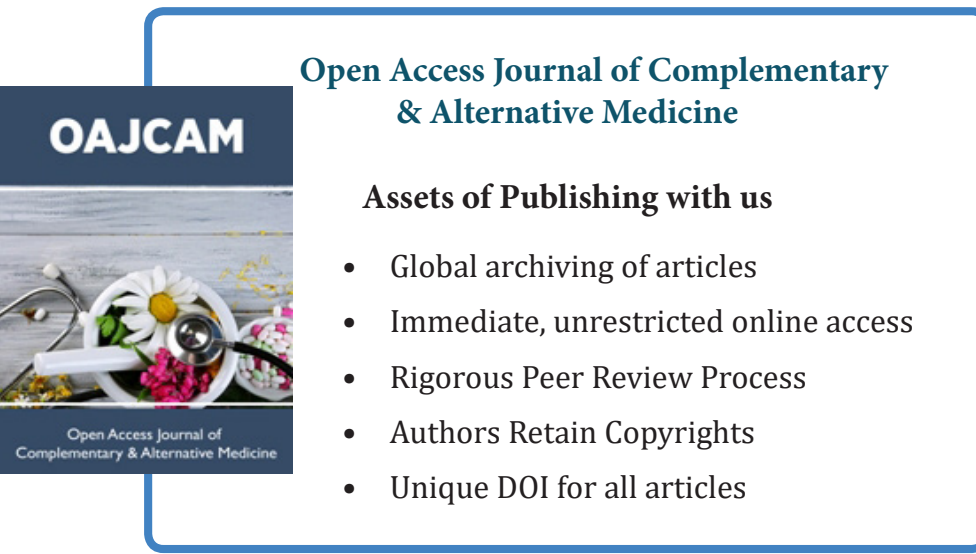

